Historic, Archive Document

Do not assume content reflects current scientific knowledge, policies, or practices. 



\section{JANUARY 26, 1920 \\ CURRENT FIELD SEED PRICE CHANGE}

We offer today's prices subject to market changes and being unsold as follows.

Blue Ribbon Red Clover ............ \$38.00 per bu. Blue Ribbon Sapling Clover............ 40.00 "

Blue Ribbon Alsike Clover ............ 38.00 “

Blue Ribbon Alfalfa $\ldots \ldots \ldots \ldots \ldots \ldots \ldots \ldots, 28.00$ “
Blue Ribbon Timothy $\ldots \ldots \ldots \ldots \ldots \ldots \ldots \ldots$

Blue Ribbon Red Top ........... \$20.00 per 100 lbs. Bermuda Grass ............... 75.00

Tennessee Millet .............. German or Golden..... . . . . . . . . . 3.25 "

\section{SEED OATS}

Northern White Oats $\$ 1.20$ per bu. Black Mixed Oats...

\section{COW PEAS}

Whippoorwill - Recleaned............ \$7.00 per bu.

New Era... 7.00 "

Brabhams

7.00 " "

Mixed Peas

6.75 “

\section{SOY BEANS}

Mammoth Yellow.................. $\$ 6.00$ per bu. Holly Brook

\section{POTATOES}

All Varieties .................\$3.50 ... \$8.25 ...

Cotton bags for Clover, Timothy, Red Top and Rape 70 cents each extra, bags for other items included, F. O. B. Louisville.

\section{Wood, Stubbs \& Co., Inc. SEEDSMEN}

OFFICE AND WAREHOUSE 14th and WALNUT STS. 



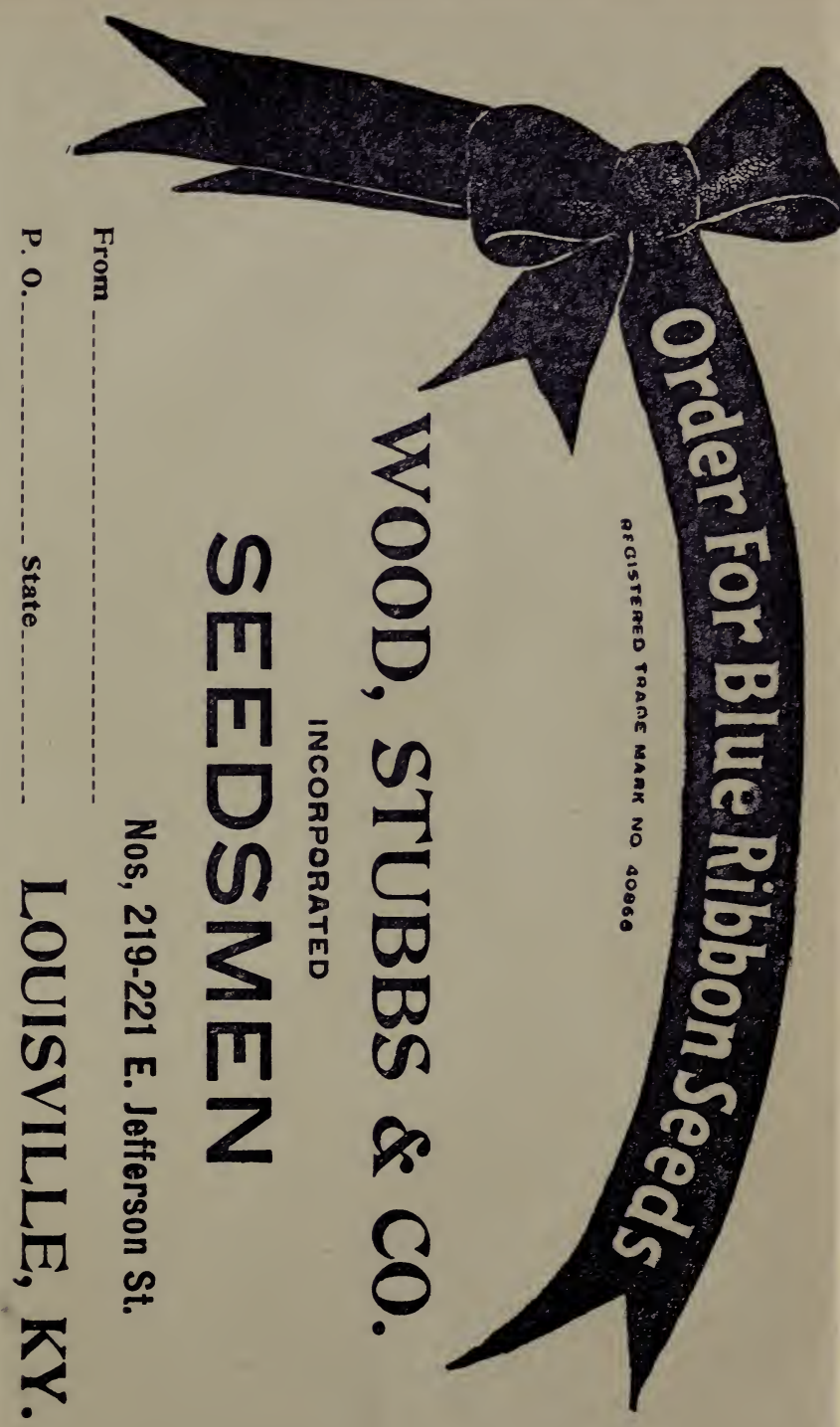




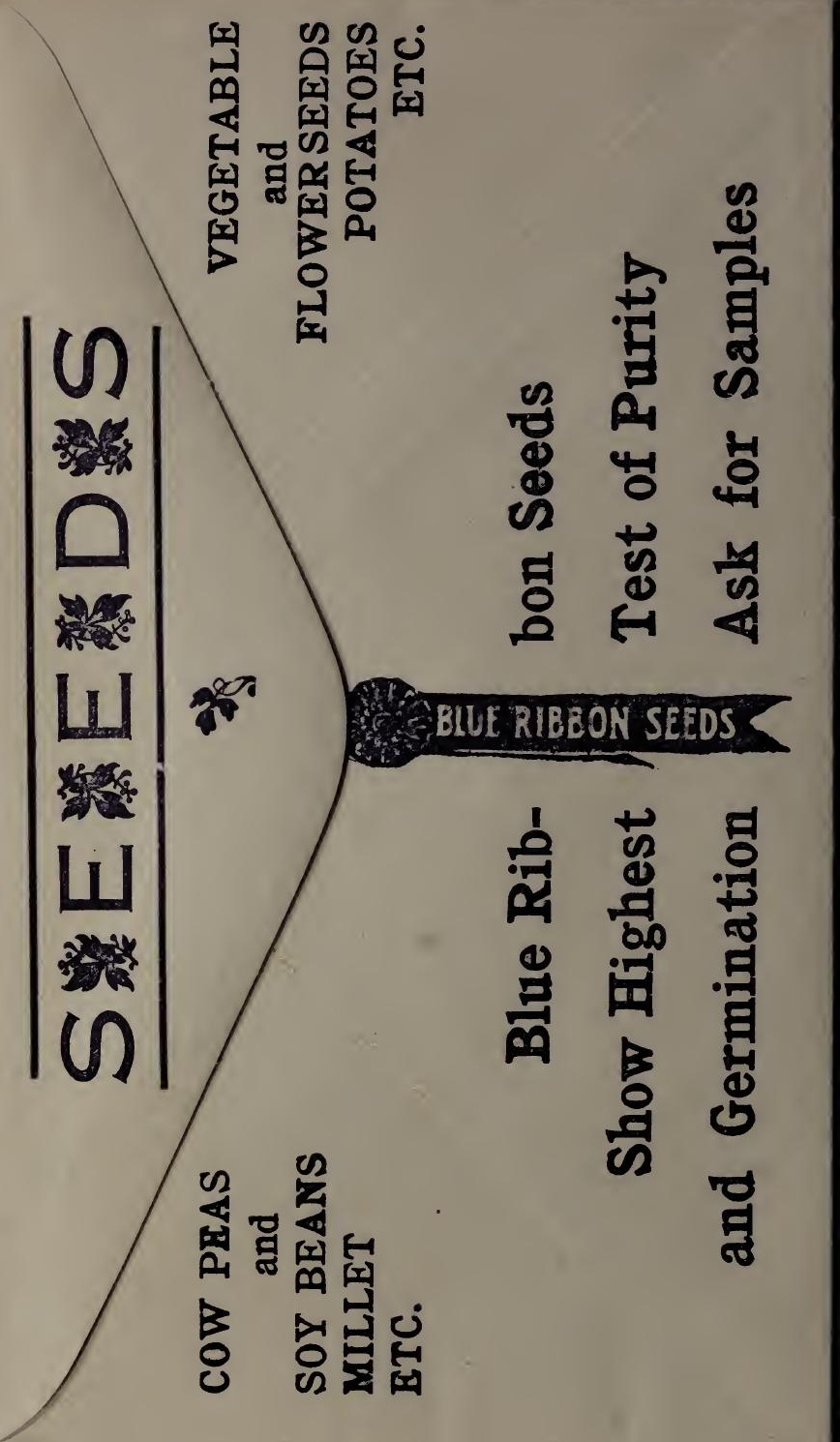

